



\section{Proficiency test for the metals copper and zinc in compound feed}

D.P.K.H. Pereboom, H. Brust and M. de Nijs 
D.P.K.H. Pereboom, H. Brust and M. de Nijs, 2021. Proficiency test for the metals copper and zinc in compound feed. Wageningen, Wageningen Food Safety Research, WFSR report 2021.015. 32 pp.; 4 fig.; 6 tab.; 11 ref.

Project number: 1227248801-WOT BPL

Project title: Borging private laboratoria (WOT BPL 20-21 PT ZnCu)

Coordinator proficiency tests: D.P.K.H. Pereboom

Project leader: M. de Nijs

Scientist: H. Brust

This report can be downloaded for free at https://doi.org/10.18174/553454 or at www.wur.eu/foodsafety-research (under WFSR publications).

(C) 2021 Wageningen Food Safety Research, institute within the legal entity Wageningen Research Foundation. Hereinafter referred to as WFSR.

The client is allowed to publish or distribute the full report to third parties. Without prior written permission from WFSR it is not allowed to:

a) publish parts of this report;

b) use this report or title of this report in conducting legal procedures, for advertising, acquisition or other commercial purposes;

c) use the name of WFSR other than as the author of this report.

P.O. Box 230, 6700 AE Wageningen, The Netherlands, T +31 (0)317 4802 56, E info.wfsr@wur.nl, www.wur.eu/food-safety-research. WFSR is part of Wageningen University \& Research.

This report from WFSR has been produced with the utmost care. However, WFSR does not accept liability for any claims based on the contents of this report.

WFSR report 2021.015

Distribution list:

- Participating laboratories 


\section{Contents}

$\begin{array}{ll}\text { Summary } & 5\end{array}$

1

$\begin{array}{ll}\text { Introduction } & 7\end{array}$

2

$\begin{array}{lr}\text { Material and methods } & 8\end{array}$

$\begin{array}{lll}2.1 & \text { Scope of the proficiency test } & 8\end{array}$

2.2 Material preparation $\quad 8$

$\begin{array}{lll}2.3 & \text { Sample identification } & 8\end{array}$

2.4 Homogeneity study $\quad 8$

$\begin{array}{lll}2.5 & \text { Stability of the materials } & 9\end{array}$

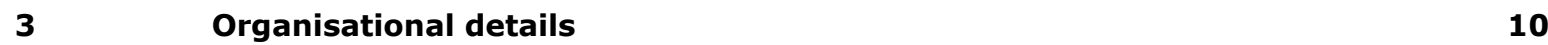

$\begin{array}{lll}3.1 & \text { Participants } & 10\end{array}$

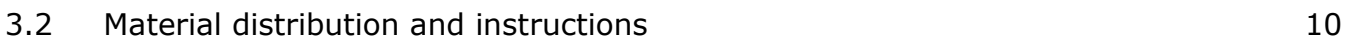

4.1 Calculation of the consensus value 11

4.2 Calculation of the uncertainty of the consensus value 11

4.3 Calculation of the standard deviation for proficiency assessment $\left(\sigma_{P}\right) \quad 12$

$\begin{array}{lll}4.4 & \text { Performance characteristics with regard to the accuracy } & 12\end{array}$

$5 \quad$ Methods and results $\quad 15$

5.1 Scope and LOQ $\quad 15$

$\begin{array}{lll}5.2 & \text { Methods of analysis applied by participants } & 15\end{array}$

$\begin{array}{lll}5.3 & \text { Performance assessment } & 16\end{array}$

$\begin{array}{llr}6 & \text { Discussion and conclusions } & 18\end{array}$

$\begin{array}{lr}\text { References } & 19\end{array}$

$\begin{array}{lll}\text { Annex } 1 & \text { Codification of the samples } & 20\end{array}$

$\begin{array}{lll}\text { Annex } 2 & \text { Instruction letter } & 21\end{array}$

Annex $3 \quad$ Statistical evaluation of homogeneity data 22

$\begin{array}{lll}\text { Annex } 4 & \text { Statistical evaluation of stability data } & 24\end{array}$

$\begin{array}{lll}\text { Annex } 5 & \text { Overview of the applied methods } & 26\end{array}$

$\begin{array}{lll}\text { Annex } 6 & \text { Results material A and B } & 28\end{array}$

$\begin{array}{lll}\text { Annex } 7 & \text { Overview performance per laboratory } & 31\end{array}$ 



\section{Summary}

A proficiency test (PT) for the determination of copper and zinc in compound feed was organised by Wageningen Food Safety Research (WFSR) between January and May 2021 in accordance with ISO/IEC 17043. WFSR is accredited for the organisation of proficiency tests in the field of contaminants, pesticides, mycotoxins, plant toxins and veterinary drugs in feed and feed ingredients according to ISO/IEC 17043 (R013). The primary goal of this proficiency test was to give participants the opportunity to evaluate and demonstrate their competence for the analysis of copper and zinc in compound feed.

For this proficiency test, two materials were prepared and dispatched. The consensus value (based on moisture content of $12 \%$ ) of the metals in each material are given in Table 1.

Table 1 Consensus values and $R S D_{R}$ of the copper and zinc in the proficiency materials.

\begin{tabular}{lcccc} 
& \multicolumn{2}{c}{ Material A (feed sows) } \\
Compound & $\begin{array}{c}\text { Consensus value } \\
\text { mg } / \mathrm{kg}\end{array}$ & $\mathrm{RSD}_{\mathrm{R}}(\%)$ & Material B (feed piglets) \\
Copper & 20.4 & 12 & 133 & 10 \\
\hline Zinc & 96.7 & 7 & 128 & 7 \\
\hline
\end{tabular}

Forty-five participants subscribed for the participation in this PT, of which 44 reported results. One participant submitted the results seven days after the closing date of reporting, but the results were nevertheless included in the evaluation. One participant was unable to report results.

Materials A and B were prepared by grinding and extensive mixing of two commercially obtained piglet and sow compound feeds. Both materials were sufficiently homogeneous and stable during the PT. Each participant received one test sample of each material.

All participants submitted results for copper and zinc. One participant analysed only material A.

For both materials (A and B), 88\% of the copper and zinc results were rated with satisfactory z-scores $(|z| \leq 2), 5 \%$ of the results fell in the range of questionable results with $2<|z|<3$, and $7 \%$ of the results fell in the range of unsatisfactory results with $|z| \geq 3$.

Thirty-three participants achieved optimal performance for both materials by detecting both metals copper and zinc with the correct quantification, the absence of false negative results and reporting within the indicated deadline. Eleven participants reported questionable or unsatisfactory z-scores. No false negative results were reported. The results of this PT on copper and zinc are summarized in Table 2.

Table 2 Summarized performance of laboratories reporting results in the proficiency test on copper and zinc in materials $A$ and $B$.

\begin{tabular}{llr} 
Compound & \# of results & Satisfactory performance (\%) \\
\hline Copper & Material A & 89 \\
\hline Zinc & 44 & 86 \\
\hline & 44 & \\
\hline Copper & Material B & 91 \\
\hline Zinc & 43 & 86 \\
\hline
\end{tabular}


Based on the results submitted by the participants of this PT it can be concluded the participants are capable of satisfactory quantification of copper and zinc in piglet and sow compound feed. The interlaboratory reproducibility $\left(\mathrm{RSD}_{\mathrm{R}}\right)$ ranged from $7-12 \%$. The satisfactory results for copper and zinc varied from 86 to $91 \%$. 


\section{Introduction}

Proficiency testing is conducted to provide participants with a powerful tool to evaluate and demonstrate the reliability of the data that are produced by the laboratory. Proficiency testing is an important requirement and demanded by ISO/IEC 17025:2017 [1].

The preparation of the materials, including the homogeneity and stability testing of the materials, and the evaluation of the quantitative results were carried out under accreditation according to ISO/IEC 17043:2010 [2] accreditation by the Dutch Accreditation Board (R013).

The maximum levels of the metals copper and zinc are regulated in Regulation (EC) No 1334/2003 [9] and amendments thereof. The maximum level (ML) for copper in complete feed for piglets, suckling and weaned up to four weeks after weaning is $150 \mathrm{mg} / \mathrm{kg}$ and from the $5^{\text {th }}$ week after weaning up to 8 weeks after weaning $100 \mathrm{mg} / \mathrm{kg}$. The ML for copper in sow compound feed is $25 \mathrm{mg} / \mathrm{kg}$. For zinc, the MLs for both the piglet feed and sow compound feed are $150 \mathrm{mg} / \mathrm{kg}$.

The aim of this proficiency test was to give participants the opportunity to evaluate or demonstrate their competence for the analysis of copper and zinc in piglets and sow compound feed. 


\section{Material and methods}

\subsection{Scope of the proficiency test}

This proficiency test (PT) focused on the metals copper and zinc in compound feed, using commercially obtained piglet and sow compound feed as representative matrices. The target concentrations aimed for are presented in Table 3 and took the regulatory limits into account.

Table 3 Target concentrations $\mathrm{mg} / \mathrm{kg}$ of copper and zinc in the PT materials.

\begin{tabular}{lcc} 
& \multicolumn{2}{c}{ Target concentrations $(\mathrm{mg} / \mathrm{kg})$} \\
Compound & Material A (sow feed) & Material B ( piglet feed) \\
Copper & 25 & 150 \\
\hline Zinc & 100 & 150 \\
\hline
\end{tabular}

\subsection{Material preparation}

For preparation of the two PT materials A and B, respectively, commercial piglet and sow compound feed were used. For each material, three kilograms were milled using a centrifugal mill (ZM 200, Retsch, Haan) to obtain a particle size of $500 \mu \mathrm{m}$. The materials were homogenised by extensive mixing using a Stephan Cutter UM12 according to the in-house standard operating procedure [3].

\subsection{Sample identification}

After homogenization, materials A and B were divided into sub-portions of approximately 25 grams and stored in polypropylene, airtight closed tubes of $50 \mathrm{ml}$ at room temperature until use.

The samples for the participants were randomly selected and coded using a web application designed for PTs. The code used was "2021/metals/compound feed/000", in which the three digit number of the code was automatically generated by the WFSR Laboratory Quality Services web application. One sample set was prepared for each participant. Each sample set consisted of one randomly selected sample of material A and one of material B. The codes of the samples for each sample set are presented in Annex 1. The samples for homogeneity and stability testing were also randomly selected tubes of material $A$ and $B$.

\section{$2.4 \quad$ Homogeneity study}

To verify the homogeneity of the PT materials, ten containers of material A and B were analysed in duplicate for copper and zinc.

The homogeneity of both materials was evaluated according to The International Harmonized Protocol for Proficiency Testing of Analytical Laboratories [6] and ISO 13528:2015 [4] taking into account the insights discussed by Thompson [5] regarding the Horwitz equation. With this procedure the betweensample standard deviation $\left(\mathrm{s}_{\mathrm{s}}\right)$ and the within-sample standard deviation $\left(\mathrm{s}_{\mathrm{w}}\right)$ were compared with the standard deviation for proficiency assessment. The method applied for homogeneity testing is considered suitable if $\mathrm{s}_{\mathrm{w}}<0.5^{*} \sigma_{\mathrm{p}}$ and a material is considered adequately homogeneous if $\mathrm{s}_{\mathrm{s}}<0.3^{*} \sigma_{\mathrm{p}}$. 
Ten containers of material A and B were analysed in duplicate to determine the homogeneity of the materials. Both materials proved to be sufficiently homogeneous for this PT. The results of the homogeneity study, grand means with the corresponding RSD, are presented in Table 4. The results of the statistical evaluation of materials A and B are presented in Annex 3.

Table 4 Concentration of copper and zinc in materials A and B obtained during homogeneity testing.

\begin{tabular}{|c|c|c|c|c|}
\hline \multirow[t]{3}{*}{ Material code } & \multicolumn{2}{|c|}{ Material A } & \multicolumn{2}{|c|}{ Material B } \\
\hline & Concentration & RSD & Concentration & RSD \\
\hline & $\mathrm{mg} / \mathrm{kg}$ & $\%$ & $\mathrm{mg} / \mathrm{kg}$ & $\%$ \\
\hline Zinc & 98.2 & 2.22 & 132 & 1.86 \\
\hline
\end{tabular}

\subsection{Stability of the materials}

The stability of copper and zinc in the PT materials was assessed according to the procedures [5, 7]. On March 29th, 2021 , the day of distribution of the PT samples, six randomly selected tubes of each material $A$ and $B$ were stored at $-20^{\circ} \mathrm{C}$. Under these conditions it is assumed that copper and zinc are stable in the materials. In addition, six samples of each material were stored at room temperature.

On May $17^{\text {th }}, 2021,49$ days after distribution of the samples, six samples of materials $A$ and $B$, that were stored at $-20^{\circ} \mathrm{C}$ and at room temperature, were analysed. For each set of test samples, the average of the results and the standard deviation were calculated.

It was determined whether a consequential instability of the analytes had occurred [5, 7] in the materials stored at room temperature. A consequential instability is observed when the average value of an analyte in the samples stored at room temperature is more than $0.3 \sigma_{p}$ below the average value of the analyte in the samples stored at $-20^{\circ} \mathrm{C}$. If so, the instability has a significant influence on the calculated z-scores.

The results of the stability of materials A and B in this PT are presented in Annex 4. None of the tested storage conditions caused a consequential difference for the analytes in both materials. Copper and zinc in the materials were, therefore, considered stable for the duration of the PT. 


\section{Organisational details}

\subsection{Participants}

Forty-five participants registered for the participation in the PT and 44 participants reported their results. Of the laboratories 39 were situated in Europe, one in Oceania and five in Asia. One participant was unable to report result due to custom clearance issues of the samples. Each participant was free to use their method of choice reflecting their routine procedures. The participants were asked to report the results through an existing web application designed for proficiency tests organised by WFSR.

\subsection{Material distribution and instructions}

Each participant received a randomly assigned laboratory code, generated by the web application. The sets of samples with the corresponding number, consisting of two coded samples (Annex 1) were sent to the PT participants on the $29^{\text {th }}$ of March 2021. The sets of samples were dispatched by courier to the participants in carton boxes. The participants were asked to store the samples at room temperature and to analyse the samples according to their routine practice. As reported by the participants, all parcels were received in good order. One parcel took 5 weeks to reach the laboratory.

The samples were accompanied by a letter with instructions for the requested analysis (Annex 2) and an acknowledgement of receipt form. In addition, by e-mail, each participant received instructions on how to use the web application to report the results. Results should be reported as $\mathrm{mg} / \mathrm{kg}$ product (relative to a feed with a moisture content of $12 \%$ ). Participants were asked to provide information on their analytical method (sample preparation procedure, internal standards used, detection technique, limit of detection, limit of quantification).

A single analysis result for both the metals copper and zinc in each sample was requested. The deadline for submitting the quantitative results was the $10^{\text {th }}$ of May 2021, allowing the participants six weeks for analysis of the test samples. All results, except one, were submitted within the deadline. Participant PT8863 was unable to report results in time due to the long delivery time of the sample. The participant reported the results 1.5 week later than the target deadline. This was not be seen as exceeding the deadline. 


\section{Statistical evaluation}

The statistical evaluation was carried out according to the International Harmonized Protocol for the Proficiency Testing of Analytical Laboratories [6], elaborated by ISO, IUPAC and AOAC and ISO 13528:2015 [4] in combination with the insights published by the Analytical Methods Committee [7,8] regarding robust statistics.

For the evaluation of the quantitative results, the consensus value, the uncertainty of the consensus value, the standard deviation for proficiency assessment and z-scores were calculated according to inhouse standard operating procedure [11].

\subsection{Calculation of the consensus value}

The consensus value $(X)$ was determined using robust statistics $[4,7,8]$. The advantage of robust statistics is that all values are taken into account: outlying observations are retained, but given less weight. Furthermore, it is not expected to receive normally distributed data in a proficiency test. When using robust statistics, the data do not have to be normally distributed in contrast to conventional outlier elimination methods.

The robust mean of the reported results of all participants, calculated from an iterative process that starts at the median of the reported results using a cut-off value depending on the number of results, was used as the consensus value $[4,7]$.

\subsection{Calculation of the uncertainty of the consensus value}

The uncertainty of the consensus value is calculated to determine the influence of this uncertainty on the evaluation of the participants. A high uncertainty of the consensus value will lead to a high uncertainty of the calculated participants $\mathrm{Z}_{\mathrm{a}}$-scores. If the uncertainty of the consensus value and thus the uncertainty of the $\mathrm{z}_{\mathrm{a}}$-score is high, the evaluation could indicate unsatisfactory method performance without any cause within the laboratory. In other words, illegitimate conclusions could be drawn regarding the performance of the participating participants from the calculated $z_{a}$-scores if the uncertainty of the consensus value is not taken into account.

The uncertainty of the consensus value (the robust mean) is calculated from the estimation of the standard deviation of the consensus value and the number of values used for the calculation of the consensus value [4] and is calculated using the formula:

$\mathrm{u}=1.25 * \frac{\hat{\sigma}}{\sqrt{\mathrm{n}}}$

where:

$\mathrm{u}=$ Uncertainty of the consensus value;

$\mathrm{n}=$ Number of values used to calculate the consensus value;

$\hat{\sigma}=$ The estimate of the standard deviation of the consensus value resulting from robust statistics. 
According to ISO $13528: 2015$ [4] the uncertainty of the consensus value $(u)$ is negligible and therefore does not have to be included in the statistical evaluation if:

$u \leq 0.3 \sigma_{\mathrm{p}}$

where:

$\mathrm{u}=$ The uncertainty of the consensus value;

$\sigma_{\mathrm{P}}=$ Standard deviation for proficiency assessment (§3.3).

In case the uncertainty of the consensus value does not comply with this criterion, the uncertainty of the consensus value should be taken into account when evaluating the performance of the participants regarding the accuracy (§3.4). In case the uncertainty is $>0.7 \sigma_{\mathrm{p}}$ the calculated $z$-scores should not be used for evaluation of participants performance and are presented for information only.

\subsection{Calculation of the standard deviation for proficiency assessment $\left(\sigma_{P}\right)$}

According to Commission Decision 2002/657/EC [10], the coefficient of variation for the repeated analysis of a reference or fortified material under reproducibility conditions, shall not exceed the level calculated by the Horwitz equation. The Horwitz equation, $\sigma_{H}=0.02 c^{0.8495}$, presents a useful and widespread applied relation between the expected relative standard deviation of a singular analysis result under reproducibility conditions, and the concentration, $c(\mathrm{~g} / \mathrm{g})$. It expresses inter-laboratory precision expected in inter-laboratory trials. Therefore, this relation is suitable for calculating the standard deviation for proficiency assessment in proficiency tests $\left(\sigma_{P}\right)$.

Thompson [7] demonstrated that the Horwitz equation is not applicable to the lower concentration range $(<120 \mu \mathrm{g} / \mathrm{kg})$ as well as to the higher concentration range $(>138 \mathrm{~g} / \mathrm{kg})$. Therefore a complementary model is suggested:

For analyte concentrations $<120 \mu \mathrm{g} / \mathrm{kg}$ :

$\sigma_{\mathrm{P}} \quad=\quad 0.22 \mathrm{c}$

For analyte concentrations $>138 \mathrm{~g} / \mathrm{kg}$ :

$\sigma_{\mathrm{P}} \quad=\quad 0.01 \mathrm{c}^{0.5}$

where:

$\sigma_{\mathrm{P}} \quad=\quad$ Expected standard deviation in proficiency tests;

c $=$ Concentration of the analyte $(\mathrm{g} / \mathrm{g})$.

\subsection{Performance characteristics with regard to the accuracy}

For illustrating the performance of the participating participants with regard to the accuracy a $\mathrm{Z}_{\mathrm{a}}$-score is calculated. For the evaluation of the performance of the participants, ISO 13528:2015 [4] is applied. According to these guidelines Za-scores are classified as presented in Table 5 .

Table 5

Classification of $Z_{a}$-scores.

\begin{tabular}{cc}
\hline$\left|z_{a}\right| \leq 2$ & Satisfactory \\
\hline $2<\left|z_{a}\right|<3$ & Questionable \\
\hline$\left|z_{a}\right| \geq 3$ & Unsatisfactory
\end{tabular}


If the calculated uncertainty of the consensus value complies with the criterion mentioned in $\S 3.2$, the uncertainty is negligible. In this case the accuracy z-score is calculated from equation I:

$z_{a}=\frac{\bar{X}-X}{\sigma_{P}}$

Equation I

where:

$z_{a}=$ Accuracy z-score;

$\bar{x}=$ The average result of the laboratory;

$\mathrm{X}=$ Consensus value;

$\sigma_{\mathrm{P}}=$ Standard deviation for proficiency assessment.

However, if the uncertainty of the consensus value does not comply with the criterion mentioned in $\S 3.2$, it could influence the evaluation of the participants. Although, according to ISO 13528 in this case no z-scores can be calculated, we feel that evaluation of the participating participants is of main importance justifying the participating participants' effort. Therefore in this case, the uncertainty is taken into account by calculating the accuracy z-score [4] using equation II:

$z_{a}^{\prime}=\frac{x-X}{\sqrt{\sigma_{p}^{2}+u^{2}}}$

Equation II

where:

$\mathrm{z}^{\prime}{ }_{\mathrm{a}}=$ Accuracy $\mathrm{z}$-score taking into account the uncertainty of the consensus value;

$\bar{x}=$ The average result of the laboratory;

$\mathrm{X}=$ Consensus value;

$\sigma_{p}=$ Standard deviation for proficiency assessment;

$\mathrm{u}=$ Uncertainty of the consensus value.

A consequential instability of the proficiency materials can influence the evaluation of the laboratory performance. Therefore, in that case the consequential instability is taken into account when calculating z-scores. Because instability only regards one side of the confidence interval (a decrease of the concentration) this correction only applies to the lower $2 \mathrm{~s}$ limit and results in an asymmetrical confidence interval.

In the case of a consequential instability the accuracy z-score for the participants that reported an amount below the consensus value is corrected for this instability using equation III:

$z_{\mathrm{ai}}=\frac{\bar{X}-X}{\sqrt{\sigma_{p}^{2}+\Delta^{2}}}$

Equation III

where:

$\mathrm{Z}_{\mathrm{ai}}=$ Accuracy $z$-score taking into account the instability of the consensus value;

$\bar{x}=$ The average result of the laboratory;

$\mathrm{X}=$ Consensus value;

$\sigma_{\mathrm{p}}=$ Standard deviation for proficiency assessment;

$\Delta=$ Difference between average concentration of compound stored at $-20^{\circ} \mathrm{C}$ and stored at room temperature.

In some cases the uncertainty of the consensus value does not comply with the criterion in $\S 3.2$ and a consequential instability is observed. In this case the $\mathrm{z}^{\prime}{ }^{a}$-score for the participants that reported an amount below the consensus value is corrected for this instability using equation IV:

$z^{\prime}{ }_{a i}=\frac{X-X}{\sqrt{\sigma_{p}^{2}+\Delta^{2}+u^{2}}}$

Equation IV 
where:

$\mathrm{z}^{\prime}{ }_{\mathrm{ai}}=$ Accuracy $\mathrm{z}$-score taking into account the uncertainty and instability of the consensus value;

$\bar{x}=$ The average result of the laboratory;

$\mathrm{X}=$ Consensus value;

$\sigma_{\mathrm{P}} \quad=$ Standard deviation for proficiency assessment;

$\Delta=$ Difference between average concentration of compound stored at $-20^{\circ} \mathrm{C}$ and stored at room temperature;

$\mathrm{u}=$ Uncertainty of the consensus value. 


\section{$5 \quad$ Methods and results}

\subsection{Scope and LOQ}

This PT was dedicated to copper and zinc in piglets and sow compound feed. Ranges for the reported limits of detection (LODs) and limits of quantifications (LOQs) for copper and zinc are presented in Annex 5. Ten participants provided no details of the LODs and LOQs of the method used.

All the participants determined and quantified copper and zinc as was requested. One participant analysed only material $A$.

The LODs reported by the participants ranged from 0.0044 to $4 \mathrm{mg} / \mathrm{kg}$ for copper and 0.00053 to $5.6 \mathrm{mg} / \mathrm{kg}$ for zinc. LOQs provided by the participants ranged from 0.02 to $12.5 \mathrm{mg} / \mathrm{kg}$ for copper and from 0.005 to $20 \mathrm{mg} / \mathrm{kg}$ for zinc.

\subsection{Methods of analysis applied by participants}

An overview of the information provided by the participants regarding the methods applied in this PT is presented in Annex 5. Each participant was free to use their method of choice reflecting their routine procedures. The information provided was not always complete. Six participants provided no information at all.

Eighteen laboratories applied ICP-MS (inductively coupled plasma mass spectrometry) for the identification and quantification of the metals, nine laboratories applied ICP-AES (inductively coupled plasma atomic emission spectroscopy) also referred as inductively coupled plasma optical emission spectrometry (ICP-OES), eight laboratories applied FAAS (flame atomic absorption spectroscopy). One laboratory applied ICP-MS as well as AAS (atomic absorption spectroscopy), one applied multi-element photo detector, while seven laboratories did not report the detection technique.

Twenty-three laboratories used microwave digestion for sample preparation and therefore different acid digestion procedures were employed for the determination of elements in compound feed. Five laboratories carried out the acid digestions with a mixture of nitric acid and hydrogen peroxide to bring the sample in the form of a solution in order to introduce it into the analyser, three laboratories used nitric acid and hydrochloric acid, three laboratories used only nitric acid and 12 laboratories used microwave digestion but without further specifications. Eight laboratories dry-ashed the sample. One participant digested the sample with a mixture of nitric acid and hydrogen peroxide and diluted the extract for measurement. Two laboratories digested the sample with a mixture of nitric acid and hydrogen peroxide without further specifications. Ten laboratories provided no details on the sample preparation conditions they used.

Out of 44 participants, 17 laboratories used one or more internal standards for copper and zinc quantification and 10 did not use an internal standard. The internal standards used were: beryllium, gallium, germanium, indium, iridium, lithium, rhodium, scandium and ytterbium. One participant used a standard of zinc as standard reference material (SRM) And one used a certified reference sample of tomato leaves to calculate recovery. Sixteen laboratories provided no information. 


\subsection{Performance assessment}

The quantitative performance was assessed through z-scores. The individual z-scores obtained by each participant, including their graphical representation, for copper and zinc in materials A and B are summarised in Annex 6. A summary of the performance of the participants in this PT is provided in Annex 7.

A summary of the statistical evaluation of the PT results is presented in Table 6 . This table includes all relevant parameters: the consensus value (CV), the uncertainty of the assigned value (u), the standard deviation for proficiency assessment $\left(\sigma_{p}\right)$ and the robust (relative) standard deviation, based on participants' results.

Table 6 Parameters of copper and zinc and summary in material $A$ and $B$.

\begin{tabular}{|c|c|c|c|c|}
\hline & \multicolumn{2}{|c|}{ Material A } & \multicolumn{2}{|c|}{ Material B } \\
\hline & Copper & Zinc & Copper & Zinc \\
\hline $\mathrm{CV}(\mathrm{mg} / \mathrm{kg})$ & 20.4 & 96.7 & 133 & 128 \\
\hline$\sigma_{p}(\mathrm{mg} / \mathrm{kg})$ suggested by Horwitz & 2.07 & 7.77 & 10.2 & 9.85 \\
\hline$\sigma_{p}(\%)$ & 10.2 & 8.04 & 7.66 & 7.71 \\
\hline robust $\sigma(\mathrm{mg} / \mathrm{kg})$ & 2.38 & 6.55 & 13.8 & 9.15 \\
\hline robust $\sigma(\%)\left(R_{S D}\right)$ & 11.7 & 6.77 & 10.3 & 7.16 \\
\hline \# reported & 44 & 44 & 43 & 43 \\
\hline$|z| \geq 3$ & 2 & 4 & 2 & 4 \\
\hline Satisfactory z-scores (\%) & 89 & 86 & 91 & 86 \\
\hline
\end{tabular}

The consensus values for copper and zinc in material A were respectively 20.4 and $96.7 \mathrm{mg} / \mathrm{kg}$ and in material B respectively 133 and $128 \mu \mathrm{g} / \mathrm{kg}$.

For copper and zinc in both materials, the uncertainty of the consensus value did comply with the criterion $u \leq 0.3 \sigma_{\mathrm{p}}$ and was, therefore, considered as negligible in the evaluation of the $z$-scores.

For material A, three of the reported results for copper were questionable results (PT8860, PT8863 and PT8883) and two results were unsatisfactory (PT8857 and PT8876). For zinc two results were questionable (PT8875 and PT8879) and four results were unsatisfactory (PT8857, PT8867, PT8876 and PT8890). For material B, two of the reported results for copper were questionable results (PT8859 and PT8867) and two results were unsatisfactory (PT8857 and PT8875). For zinc two results were questionable (PT8847 and PT8879) and four results were unsatisfactory (PT8857, PT8867, PT8875 and PT8890).

The robust relative standard deviation $\left(R \mathrm{RD}_{\mathrm{R}}\right)$ was calculated according to ISO13528:2015 [4] for informative purposes only. In this study it was used as a good estimation of the interlaboratory variability. The RSDR values for copper and zinc in both materials are shown in Annex 6 and in Table 6. For both materials ( $A$ and $B$ ), the robust standard deviations $\left(R S D_{R}\right)$ of the reported results were comparable with standard deviation suggested by Horwitz $\left(\sigma_{p}\right)$. The RSDR for copper and zinc in material $A$ were respectively $12 \%$ and $7 \%$ and the $\sigma_{p}$ were respectively $10 \%$ and $8 \%$. In material $B$ the $\mathrm{RSD}_{\mathrm{R}}$ for copper and zinc were respectively $10 \%$ and $7 \%$ and the $\sigma_{\mathrm{p}}$ were for both metals $8 \%$. The lower RSDR for zinc in both materials shows that the laboratories' performance for zinc was slightly better than for copper. 
For the individual metals in material $A$, the percentage of satisfactory results for copper was $89 \%$ and for zinc $86 \%$. For the combined results of copper and zinc in material $A, 88 \%$ of the results were rated with satisfactory $z$-scores $(|z| \leq 2), 5.7 \%$ of the results felt into the questionable range with $2<|z|<3$ and $6.8 \%$ of the results fell into the unsatisfactory range with $|z| \geq 3$.

For the individual metals in material B, the percentage of satisfactory results for copper was $91 \%$ and for zinc $86 \%$. For the combined results of copper and zinc in material A, $88 \%$ of the results were rated with satisfactory $z$-scores $(|z| \leq 2), 5 \%$ of the results felt into the questionable range with $2<|z|<3$ and $7 \%$ of the results fell into the unsatisfactory range with $|z| \geq 3$.

Overall, $88 \%$ of the copper and zinc results obtained for both materials ( $A$ and $B$ ) were rated with satisfactory $z$-scores $|z| \leq 2,5 \%$ of the results felt into the questionable range with $2<|z|<3$ and $7 \%$ of the results fell into the unsatisfactory range with $|z| \geq 3$.

Participant PT8857 reported unsatisfactory results for copper and zinc in material A. Based on the results of participant PT8857, it can be speculated that the results for copper and zinc have been interchanged by the participant. Participant PT8876 analysed only material A and reported very high results for material $A$. Based on these results, it can be speculated that the batch numbers of the samples during reporting on the web application have been changed by the participant.

In Annex 7 an overview of the overall performance of each participant in this PT is summarised. For the two materials combined, a maximum of 4 satisfactory z-scores could be obtained, and ' 4 out of 4' therefore reflects an optimal performance in terms of scope and capability for quantitative determination. All the participants analysed the materials for both copper and zinc. Out of 44 participants, 33 participants achieved optimal performance for both materials by detecting copper and zinc with correct quantification, the absence of false positive and/or false negative results, and reporting all results within the set deadline. 


\section{Discussion and conclusions}

Forty-five participants subscribed for the proficiency test on copper and zinc in compound for piglets and sows and 44 participants reported their results.

Two materials were sent to each participant. The metals copper and zinc were homogeneously distributed in both materials. An overview of each participant's performance is shown in Annex 7 and a summary of the results is presented in Table 6.

For the individual metals in material A, the percentage of satisfactory results for copper was $89 \%$ and for zinc $86 \%$. The robust standard deviations $\left(R S D_{R}\right)$ of the reported results were comparable with the standard deviation suggested by Horwitz.

For the individual metals in material $B$, the percentage of satisfactory results for copper was $91 \%$ and for zinc $86 \%$. The robust standard deviations $\left(R S D_{R}\right)$ of the reported results were comparable with the standard deviation suggested by Horwitz. One participant did not analyse copper and zinc in material B.

Overall, for copper and zinc in both materials combined, $88 \%$ of the results were rated with satisfactory $z$-scores $|z| \leq 2,5 \%$ of the results fell into the questionable range with $2<|z|<3$ and $7 \%$ of the results fell into the unsatisfactory range with $|z| \geq 3$. Out of 44 participants 33 showed optimal performance for both materials by detecting copper and zinc with a correct quantification, the absence of false positive or false negative results and reporting within the deadline. Eleven participants reported questionable or unsatisfactory z-scores. A total of 9 questionable z-scores and 12 unsatisfactory z-scores was reported.

Based on the results of this proficiency test it was concluded that:

- The satisfactory results for copper and zinc varied from $86-91 \%$ in this proficiency test.

- The interlaboratory reproducibility $\left(R_{S D_{R}}\right)$ ranged from $7-12 \%$ which is comparable with the standard deviation suggested by Horwitz ( $8-10 \%)$.

- Overall results of this PT: $75 \%$ of the participants showed optimal performance and are capable of satisfactory determination of copper and zinc in compound feed for piglets and for sows.

- The LOQs as provided by the participants varied widely, from 0.00053 to $50 \mathrm{mg} / \mathrm{kg}$. This variation is probably caused by the different combinations of sample preparation and detection technique. 


\section{References}

1 ISO/IEC 17025:2017 (E). 2017. General Requirements for the Competence of Calibration and Testing Laboratories.

2 ISO/IEC 17043:2010. 2010. Conformity assessment - General requirements for proficiency testing.

3 SOPA0989 - De bereiding van referentiematerialen en referentiemonsters - WFSR.

4 ISO 13528:2015, IDT. 2015. Statistical methods for use in proficiency testing by inter-laboratory comparison, 1st edition.

5 Thompson M. 2000. Recent trends in inter-laboratory precision at $\mu \mathrm{g} / \mathrm{kg}$ and sub- $\mu \mathrm{g} / \mathrm{kg}$ concentrations in relation to fitness for purpose criteria in proficiency testing. Analyst. 125: 385-386.

6 Thompson M, Ellison SL, Wood R. 2006. The International Harmonized Protocol for the Proficiency Testing of Analytical Chemistry Laboratories. Pure Appl. Chem. 78(1):145-196.

7 Analytical Methods Committee. 1989. Robust statistics - How not to reject outliers Part 1. Basic concepts. Analyst 114:1693-1697.

8 Analytical Methods Committee. 1989. Robust statistics - How not to reject outliers Part 2. Inter-laboratory trials. Analyst. 114:1699-1702.

9 Regulation (EC) no 1334/2003 of 25 July amending the conditions for authorisation of a number of additives in feedingstuffs belonging to the group of trace elements

10 Commission Decision 2002/657/EC. 12 August 2002. Implementing Council Directive 96/23/EC concerning the performance of analytical methods and the interpretation of results. Official Journal. L 221:67A-76A.

11 SOPA0992 - De statistische verwerking van resultaten van proficiency testen. 


\section{Annex 1 Codification of the samples}

\begin{tabular}{|c|c|c|}
\hline Participants code & $\begin{array}{l}\text { Last three digits of codes } \\
\text { Material A* }\end{array}$ & $\begin{array}{l}\text { Last three digits of codes } \\
\text { Material B* }\end{array}$ \\
\hline PT8845 & 147 & 740 \\
\hline PT8847 & 349 & 458 \\
\hline PT8848 & 184 & 206 \\
\hline PT8849 & 234 & 766 \\
\hline PT8850 & 221 & 215 \\
\hline PT8851 & 196 & 209 \\
\hline PT8852 & 764 & 381 \\
\hline PT8853 & 735 & 814 \\
\hline PT8854 & 178 & 440 \\
\hline PT8855 & 446 & 172 \\
\hline PT8856 & 461 & 120 \\
\hline PT8857 & 266 & 513 \\
\hline PT8858 & 151 & 253 \\
\hline PT8859 & 157 & 473 \\
\hline PT8860 & 718 & 114 \\
\hline PT8861 & 237 & 171 \\
\hline PT8862 & 988 & 103 \\
\hline PT8863 & 399 & 416 \\
\hline PT8864 & 471 & 122 \\
\hline PT8865 & 854 & 722 \\
\hline PT8866 & 173 & 883 \\
\hline PT8867 & 957 & 408 \\
\hline PT8868 & 749 & 825 \\
\hline PT8869 & 762 & 734 \\
\hline PT8870 & 926 & 798 \\
\hline PT8871 & 438 & 932 \\
\hline PT8872 & 817 & 829 \\
\hline PT8873 & 442 & 633 \\
\hline PT8874 & 931 & 498 \\
\hline PT8875 & 262 & 571 \\
\hline PT8876 & 449 & 199 \\
\hline PT8878 & 879 & 756 \\
\hline PT8879 & 613 & 362 \\
\hline PT8880 & 779 & 818 \\
\hline PT8881 & 493 & 397 \\
\hline PT8882 & 697 & 675 \\
\hline PT8883 & 410 & 469 \\
\hline PT8885 & 522 & 673 \\
\hline PT8886 & 945 & 623 \\
\hline PT8887 & 676 & 997 \\
\hline PT8888 & 388 & 116 \\
\hline PT8889 & 572 & 679 \\
\hline PT8890 & 325 & 508 \\
\hline PT8891 & 464 & 288 \\
\hline
\end{tabular}

* All sample codes start with 2021/metals/compound feed/ 


\section{Annex 2 Instruction letter}

WAGENINGEN

UNIVERSITY \& RESEARCH

Thank you very much for your interest in the proficiency test for the analysis of the metals copper and zinc in compound feed. Hereby I send you a parcel containing two randomly coded samples. Each sample consists of approximately 25 grams of test material.

Please fill out the accompanying acknowledgement of receipt form and return it immediately upon receipt of the samples, preferably by e-mail (pt.wfsr@wur.nl)

Instructions:

After arrival store the samples at room temperature.

Before analysis, homogenise them according to your laboratory's procedure.

Treat the test material as if it was a sample for routine analysis.

Please use the web application for entering your results

(https://crlwebshop.wur.nl/apex/f?p=307:LOGIN). Information about the use of this web application was sent to you earlier by e-mail.

Report all results relative to a feed with a moisture content of $12 \%$. When a metal is not within your scope, please report ' $n$ '' (not tested) in the web application. Do not use the option 'detected' from the web application. When a metal is 'not detected' or the result is below your LOQ, report the result as $<\mathrm{LOQ}$-value and specify the value (e.g. $<20 \mathrm{mg} / \mathrm{kg}$ ).

The deadline for submitting test-results for this test is $\mathbf{1 0}$ th of May 2021.

Your username is:

Your password is:

Your lab code to enter this proficiency test is:

Please inform us about your applied method and detection technique (via the web application).

Please contact me if you have any questions or need any assistance.

With kind regards,

$$
\text { D. Pereloom }
$$

Diana Pereboom

Organiser proficiency tests

ant

March 29, 2021

Instructions proficiency test metals cogoser and zinc in compound feed.

2112554/WF5R

pomencens

P.O. Box 230

6700 AE WAGENINGEN

The Netherands

Wageningen Campus

Building 123

Auilang 123

6708 WB WAGENINGEN

amiean

www.mur.nl

09098104

Hensudem

D.P.K.H. Pereboom - de Faum

In:men

$+31(0) 614323017$

pt.wtsrewwur.ni 


\section{Annex 3 Statistical evaluation of homogeneity data}

\begin{tabular}{|c|c|c|}
\hline \multirow[b]{2}{*}{ Sample No. } & \multicolumn{2}{|c|}{ Copper in material A ( $\mathrm{mg} / \mathrm{kg})$} \\
\hline & Replicate 1 & Replicate 2 \\
\hline Hom/A001 & 20.9 & 21.4 \\
\hline Hom/A002 & 19.7 & 20.9 \\
\hline Hom/A003 & 19.5 & 19.7 \\
\hline Hom/A004 & 20.1 & 19.5 \\
\hline Hom/A005 & 19.9 & 20.4 \\
\hline Hom/A006 & 20.0 & 19.4 \\
\hline Hom/A007 & 20.3 & 20.8 \\
\hline Hom/A008 & 19.8 & 19.7 \\
\hline Hom/A009 & 19.8 & 19.7 \\
\hline Hom/A010 & 19.5 & 20.1 \\
\hline Grand mean & \multicolumn{2}{|c|}{20.0} \\
\hline \multicolumn{3}{|l|}{ Cochran's test } \\
\hline C & \multicolumn{2}{|c|}{0.464} \\
\hline $\mathrm{C}_{\text {crit }}$ & \multicolumn{2}{|c|}{0.602} \\
\hline$C<C_{\text {crit }}$ ? & \multicolumn{2}{|c|}{ NO OUTLIERS } \\
\hline Target $s=\sigma_{p}$ & \multicolumn{2}{|c|}{2.04} \\
\hline$s_{x}$ & \multicolumn{2}{|c|}{0.492} \\
\hline $\mathrm{S}_{w}$ & \multicolumn{2}{|c|}{0.391} \\
\hline $\mathrm{S}_{\mathrm{s}}$ & \multicolumn{2}{|c|}{0.407} \\
\hline Critical $=0.3 \sigma_{\mathrm{p}}$ & \multicolumn{2}{|c|}{0.613} \\
\hline Ss $<$ critical? & \multicolumn{2}{|c|}{ ACCEPTED } \\
\hline $\mathrm{s}_{\mathrm{w}}<0.5 \sigma_{\mathrm{p}} ?$ & \multicolumn{2}{|c|}{ ACCEPTED } \\
\hline
\end{tabular}

$\mathrm{S}_{\mathrm{x}}=$ Standard deviation of the sample averages.

$\mathrm{S}_{\mathrm{w}}=$ Within-sample standard deviation.

$\mathrm{Ss}_{\mathrm{s}}=$ Between-sample standard deviation.

\begin{tabular}{|c|c|c|}
\hline \multirow[b]{2}{*}{ Sample No. } & \multicolumn{2}{|c|}{ zinc in material A ( $\mathrm{mg} / \mathrm{kg})$} \\
\hline & Replicate 1 & Replicate 2 \\
\hline Hom/A001 & 99.6 & 99.4 \\
\hline Hom/A003 & 96.4 & 96.5 \\
\hline Hom/A004 & 97.8 & 95.5 \\
\hline Hom/A006 & 96.9 & 99.8 \\
\hline Hom/A007 & 98.1 & 97.7 \\
\hline Hom/A008 & 104 & 98.4 \\
\hline Hom/A009 & 99.2 & 96.7 \\
\hline Hom/A010 & 100.0 & 98.4 \\
\hline $\mathrm{C}_{\text {crit }}$ & \multicolumn{2}{|c|}{0.602} \\
\hline $\mathrm{C}<\mathrm{C}_{\text {crit }} ?$ & \multicolumn{2}{|c|}{ NO OUTLIERS } \\
\hline Target $\mathrm{s}=\sigma_{\mathrm{p}}$ & \multicolumn{2}{|c|}{7.88} \\
\hline$S_{x}$ & \multicolumn{2}{|c|}{1.47} \\
\hline $\mathrm{S}_{w}$ & \multicolumn{2}{|c|}{2.26} \\
\hline $\mathrm{S}_{\mathrm{s}}$ & \multicolumn{2}{|c|}{0.00} \\
\hline Critical $=0.3 \sigma_{\mathrm{P}}$ & \multicolumn{2}{|c|}{2.36} \\
\hline $\mathrm{S}_{\mathrm{s}}<$ critical? & \multicolumn{2}{|c|}{ ACCEPTED } \\
\hline
\end{tabular}




\begin{tabular}{|c|c|c|}
\hline \multirow[b]{2}{*}{ Sample No. } & \multicolumn{2}{|c|}{ Copper in material B ( $\mathrm{mg} / \mathrm{kg})$} \\
\hline & Replicate 1 & Replicate 2 \\
\hline Hom/A001 & 128 & 133 \\
\hline Hom/A002 & 128 & 131 \\
\hline Hom/A003 & 131 & 125 \\
\hline Hom/A004 & 132 & 134 \\
\hline Hom/A005 & 126 & 134 \\
\hline Hom/A006 & 132 & 128 \\
\hline Hom/A007 & 129 & 132 \\
\hline Hom/A008 & 131 & 129 \\
\hline Hom/A009 & 126 & 131 \\
\hline $\mathrm{Hom} / \mathrm{A} 010$ & 125 & 130 \\
\hline Grand mean & \multicolumn{2}{|c|}{130} \\
\hline \multicolumn{3}{|l|}{ Cochran's test } \\
\hline C & \multicolumn{2}{|c|}{0.506} \\
\hline $\mathrm{C}_{\text {crit }}$ & \multicolumn{2}{|c|}{0.602} \\
\hline $\mathrm{C}<\mathrm{C}_{\text {crit }}$ ? & \multicolumn{2}{|c|}{ NO OUTLIERS } \\
\hline Target $\mathrm{s}=\sigma_{\mathrm{P}}$ & \multicolumn{2}{|c|}{10.1} \\
\hline$s_{x}$ & \multicolumn{2}{|c|}{1.62} \\
\hline $\mathrm{S}_{\mathrm{w}}$ & \multicolumn{2}{|c|}{3.23} \\
\hline $\mathrm{S}_{\mathrm{s}}$ & \multicolumn{2}{|c|}{0.000} \\
\hline Critical $=0.3 \sigma_{p}$ & \multicolumn{2}{|c|}{3.03} \\
\hline $\mathrm{s}_{\mathrm{s}}<$ critical? & \multicolumn{2}{|c|}{ ACCEPTED } \\
\hline $\mathrm{s}_{\mathrm{W}}<0.5 \sigma_{\mathrm{P}} ?$ & \multicolumn{2}{|c|}{ ACCEPTED } \\
\hline
\end{tabular}

\begin{tabular}{|c|c|c|}
\hline \multirow[b]{2}{*}{ Sample No. } & \multicolumn{2}{|c|}{ Zinc in material B ( $\mathrm{mg} / \mathrm{kg})$} \\
\hline & Replicate 1 & Replicate 2 \\
\hline Hom/A001 & 130 & 131 \\
\hline Hom/A002 & 134 & 134 \\
\hline $\mathrm{Hom} / \mathrm{A003}$ & 136 & 129 \\
\hline Hom/A004 & 136 & 133 \\
\hline Hom/A005 & 130 & 137 \\
\hline Hom/A006 & 134 & 130 \\
\hline Hom/A007 & 130 & 132 \\
\hline Hom/A008 & 133 & 131 \\
\hline Hom/A009 & 130 & 133 \\
\hline Hom/A010 & 128 & 130 \\
\hline Grand mean & \multicolumn{2}{|c|}{132} \\
\hline \multicolumn{3}{|l|}{ Cochran's test } \\
\hline C & \multicolumn{2}{|c|}{0.318} \\
\hline $\mathrm{C}_{\text {crit }}$ & \multicolumn{2}{|c|}{0.602} \\
\hline$C<\mathrm{C}_{\text {crit }}$ ? & \multicolumn{2}{|c|}{ NO OUTLIERS } \\
\hline Target $s=\sigma_{p}$ & \multicolumn{2}{|c|}{10.1} \\
\hline$S_{x}$ & \multicolumn{2}{|c|}{1.61} \\
\hline $\mathrm{S}_{\mathrm{w}}$ & \multicolumn{2}{|c|}{2.60} \\
\hline $\mathrm{S}_{\mathrm{s}}$ & \multicolumn{2}{|c|}{0.000} \\
\hline Critical $=0.3 \sigma_{p}$ & \multicolumn{2}{|c|}{3.04} \\
\hline $\mathrm{S}_{\mathrm{s}}<$ critical? & \multicolumn{2}{|c|}{ ACCEPTED } \\
\hline $\mathrm{s}_{\mathrm{w}}<0.5 \sigma_{\mathrm{P}} ?$ & \multicolumn{2}{|c|}{ ACCEPTED } \\
\hline
\end{tabular}




\section{Annex 4 Statistical evaluation of stability data}

Statistical evaluation for copper in material A.

\begin{tabular}{|c|c|c|}
\hline Storage temperature & $-20{ }^{\circ} \mathrm{C}$ & room temperature \\
\hline Time (days) & 0 & 49 \\
\hline \multirow[t]{4}{*}{ Calculated amounts $(\mathrm{mg} / \mathrm{kg})$} & 20.6 & 20.4 \\
\hline & 20.8 & 20.2 \\
\hline & 20.2 & 20.1 \\
\hline & 20.4 & 20.8 \\
\hline Average amount $(\mathrm{mg} / \mathrm{kg})$ & 20.3 & 20.3 \\
\hline $\mathrm{n}$ & 6 & 6 \\
\hline st. $\operatorname{dev}(\mathrm{mg} / \mathrm{kg})$ & 0.416 & 0.291 \\
\hline Difference & & 0.064 \\
\hline
\end{tabular}

Statistical evaluation for zinc in material A.

\begin{tabular}{|c|c|c|}
\hline Storage temperature & $-20{ }^{\circ} \mathrm{C}$ & room temperature \\
\hline Time (days) & 0 & 49 \\
\hline \multirow[t]{6}{*}{ Calculated amounts (mg/kg) } & 102 & 99.4 \\
\hline & 100 & 99.4 \\
\hline & 99.9 & 101 \\
\hline & 103 & 101 \\
\hline & 98.6 & 99.0 \\
\hline & 98.9 & 99.1 \\
\hline Average amount (mg/kg) & 100 & 99.8 \\
\hline $\mathrm{n}$ & 6 & 6 \\
\hline st. dev (mg/kg) & 1.66 & 0.928 \\
\hline Difference & & 0.604 \\
\hline $0.3 * \sigma_{p}$ & & 2.41 \\
\hline Consequential difference? Diff $<0.3^{*} \sigma_{\mathrm{p}}$ & & No \\
\hline
\end{tabular}




\section{Statistical evaluation for copper in material B.}

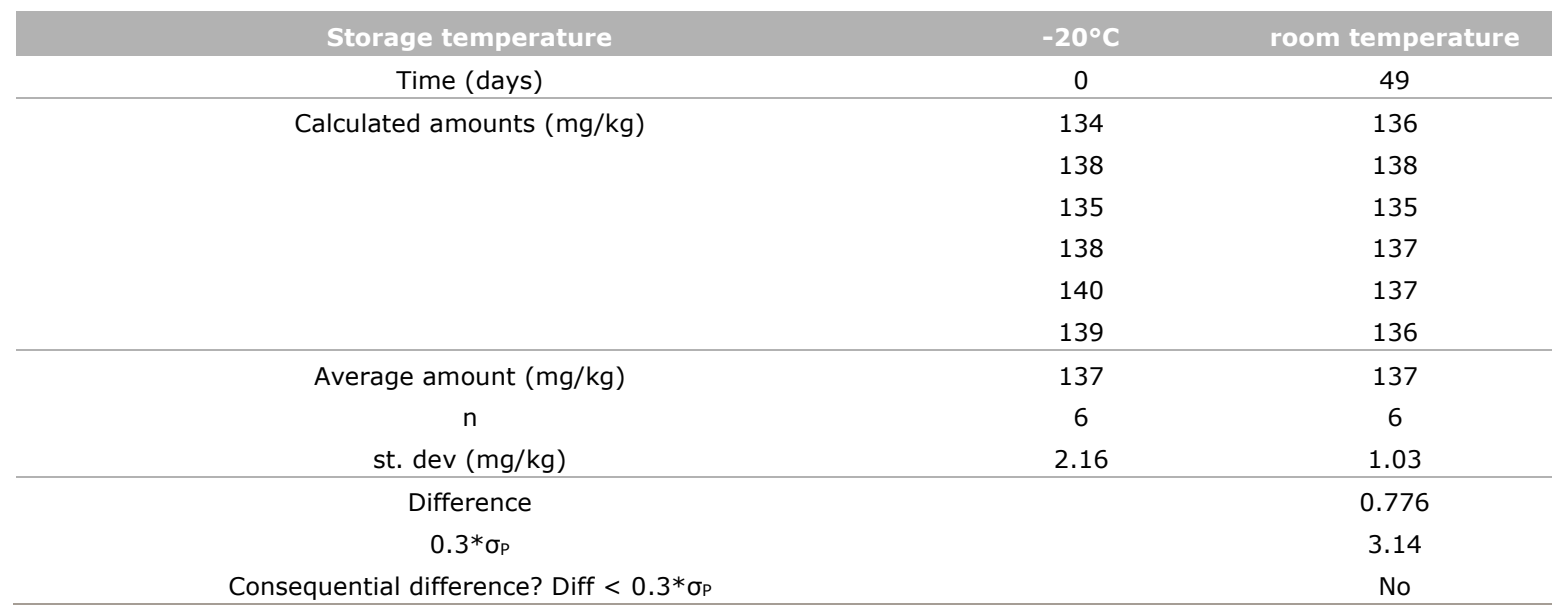

Statistical evaluation for zinc in material B.

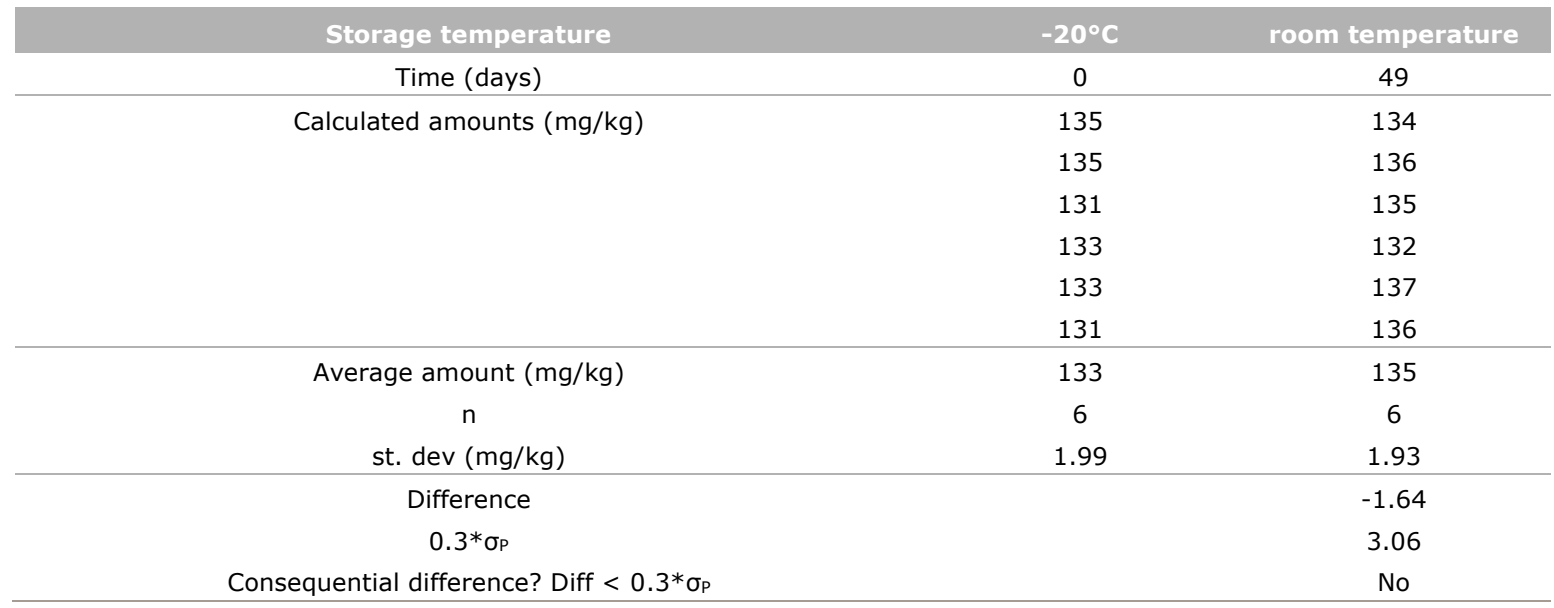




\section{Annex 5 Overview of the applied methods}

\begin{tabular}{|c|c|c|c|c|c|c|c|}
\hline \multirow[t]{2}{*}{ Lab } & \multirow[t]{2}{*}{ Sample purification } & \multirow[t]{2}{*}{ Internal standard } & \multicolumn{2}{|c|}{ LOD mg/kg } & \multicolumn{2}{|c|}{ LOQ mg/kg } & \multirow{2}{*}{$\begin{array}{l}\text { Detection } \\
\text { method }\end{array}$} \\
\hline & & & copper & zinc & copper & zinc & \\
\hline PT8845 & Microwave digestion with $\mathrm{HNO} 3$ and $\mathrm{HCL}$ & No & 0.043 & & 0.13 & 0.5 & $\begin{array}{l}\text { Multielement } \\
\text { photo detector }\end{array}$ \\
\hline PT8847 & Microwave digestion system & & $0.08 \mathrm{ppm}$ & $0.05 \mathrm{ppm}$ & & & FAAS \\
\hline PT8848 & Microwave digestion with $\mathrm{HNO} 3$ and $\mathrm{HCl}$, oxidation agent $\mathrm{H} 2 \mathrm{O} 2$ & No & 0.02 & 0.006 & & & ICP-OES \\
\hline \multicolumn{8}{|l|}{ PT8849 } \\
\hline PT8850 & Pressure digestion followed by dilution & No & 0.35 & 0.35 & 1 & 1 & ICP-OES \\
\hline PT8851 & & & & & 0.7 & 0.4 & ICP-OES \\
\hline PT8852 & $\mathrm{HNO} 3+\mathrm{H} 2 \mathrm{O} 2$ & $45 \mathrm{Sc}$ & 0.1 & 0.1 & 2 & 2 & ICP-MS \\
\hline PT8853 & Microwave destruction & $\mathrm{Rh}, \mathrm{Sc}$, Ge en Ir & & & 1 & 5 & ICP-MS \\
\hline \multicolumn{8}{|l|}{ PT8854 } \\
\hline PT8855 & & In & & & & & ICP-MS \\
\hline PT8856 & Dry ashing/ microwave digestion & & 0.3 & 0.05 & 1.0 & 0.15 & FAAS \\
\hline PT8857 & Dry ashing & No & & & & & FAAS \\
\hline PT8858 & $\begin{array}{l}\text { High pressure microwave digestion. Sample solubilised in a mixture of concentrated } \mathrm{HNO} 3 \\
\text { and } \mathrm{HCL} \text {. }\end{array}$ & Rhodium & 0.02 & 0.04 & 0.06 & 0.12 & ICP-MS \\
\hline PT8860 & Samples were digested in a microwave using $6 \mathrm{ml}$ of $\mathrm{HNO} 3$ and $2 \mathrm{ml}$ of $\mathrm{H} 2 \mathrm{O} 2$ & No & 0.01 & 0.01 & 0.025 & 0.05 & ICP-MS \\
\hline PT8861 & Microwave Digestion & Yes & 0.1 & 0.1 & 5 & 20 & ICP-OES \\
\hline PT8862 & Microwave digestion & & & & 0.1 & 0.1 & ICP-MS \\
\hline PT8863 & Microwave-assisted acid digestion & No & 4 & 2 & 12.5 & 6.25 & FAAS \\
\hline PT8864 & $\begin{array}{l}\text { Digestion of } 0.5 \mathrm{~g} \text { sample }+3 \mathrm{ml} \mathrm{HNO} 3+0,5 \mathrm{ml} \mathrm{H} 2 \mathrm{O} 2+2 \mathrm{ml} \mathrm{H} 2 \mathrm{O} \text {. Dilution to } 50 \mathrm{~g} \text { with } \\
\mathrm{H} 2 \mathrm{O} \text {. }\end{array}$ & & & & 3.7 & 18 & ICP-OES \\
\hline PT8865 & & & 0.16 & 0.54 & 0.54 & 1.79 & \\
\hline PT8866 & Closed microwave & & 0.0044 & 0.00053 & 0.05 & 0.005 & ICP-OES \\
\hline PT8867 & Microwave Digestion & Scandium & & & & & ICP-MS \\
\hline
\end{tabular}




\begin{tabular}{|c|c|c|c|c|c|c|c|}
\hline \multirow[t]{2}{*}{ Lab } & \multirow[t]{2}{*}{ Sample purification } & \multirow[t]{2}{*}{ Internal standard } & \multicolumn{2}{|c|}{ LOD mg/kg } & \multicolumn{2}{|c|}{ LOQ mg/kg } & \multirow{2}{*}{$\begin{array}{l}\text { Detection } \\
\text { method }\end{array}$} \\
\hline & & & copper & zinc & copper & zinc & \\
\hline PT8868 & Closed microwave & & 0.5 & 2 & 1.7 & 6.7 & ICP-MS \\
\hline PT8869 & $\begin{array}{l}\text { A test portion is dissolved in HCL after ashing in a muffle furnace. } \\
\text { Any silica compounds present are removed by precipitation and filtration. }\end{array}$ & No & 1.18 & 1.62 & 4 & 5 & FAAS \\
\hline PT8870 & & & & & 10 & 20 & \\
\hline PT8871 & Dry and incineration the sample & No & & & & & FAAS \\
\hline PT8872 & Pressure digestion & Ga 71 & 0.062 & 0.11 & 0.21 & 0.37 & Q-ICP-MS \\
\hline PT8873 & Microwave Digestion with $\mathrm{HNO} 3$ at $260{ }^{\circ} \mathrm{C}$ for 25 minutes & Ytterbium & 1.7 & 5.6 & 5 & 16.7 & ICP-OES \\
\hline PT8874 & Dry ashing procedure. Dissolution with $\mathrm{HCl}$. & & 1.6 & 1.6 & 3.3 & 4.2 & FAAS \\
\hline PT8875 & & & & & 0.02 & 0.1 & \\
\hline PT8876 & & Yes & & & 0.05 & 0.05 & ICP-MS \\
\hline \multicolumn{8}{|l|}{ PT8878 } \\
\hline PT8879 & $\mathrm{HNO} / \mathrm{H} 2 \mathrm{O} 2$ & $\mathrm{Rh}$ & 0.02 & 0.05 & 0.05 & 0.1 & ICP-MS \\
\hline PT8880 & Microwave mineralization with $\mathrm{HNO} 3$, addition to volume $50 \mathrm{ml}$ with distilled water, filtration & No & 3 & 3 & 5 & 5 & ICP-OES \\
\hline PT8881 & Microwave acid digestion & Ir, In, Ge & & & 3 & 50 & ICP-MS \\
\hline PT8882 & Dicrowave & No & 0.3 & 0.3 & 1 & 1 & AAS; ICP MS \\
\hline PT8883 & & & 0.013 & 0.063 & 0.02 & 1 & \\
\hline PT8885 & dry ashing & Rhodium & 2 & 2 & 4 & 4 & ICP-MS \\
\hline PT8886 & Microwave closed-vessel digestion using $\mathrm{HNO} 3$ and $\mathrm{H} 2 \mathrm{O} 2$ as oxidative reagents & indium & & & 0.05 & 0.2 & ICP-MS \\
\hline PT8887 & $\begin{array}{l}\text { Microwave oven wet-digestion: weight } 0.3-0.4 \mathrm{~g} \text { of sample, add } 6 \mathrm{~mL} \text { ultrapure } \mathrm{HNO} 3 \text { and } 2 \\
\mathrm{~mL} \mathrm{H} 2 \mathrm{O} 2\end{array}$ & $\mathrm{Ge}$ & 0.3 & 1.5 & 1 & 5 & ICP-MS \\
\hline PT8888 & Acid Digestion after dry ashed & $103 \mathrm{Rh}$ & & & & & ICP-MS \\
\hline PT8889 & Microwave destruction & & & & & & ICP-MS \\
\hline PT8890 & Samples are digested with concentrated $\mathrm{HNO} 3$ under pressure. & $\mathrm{Rh}$ & 3.3 & 3.3 & 10 & 10 & ICP-MS \\
\hline PT8891 & Droge verassing & Beryllium, Lithium & 0.5 & 0.5 & 1 & 1 & ICP-OES \\
\hline
\end{tabular}




\section{Annex 6 Results material A and B}

\begin{tabular}{|c|c|c|c|c|c|c|c|c|}
\hline \multirow[b]{2}{*}{$\begin{array}{l}\text { Lab } \\
\text { code }\end{array}$} & \multicolumn{2}{|c|}{$\begin{array}{c}\text { Material A } \\
\text { Copper } \\
\text { CV: } 20.4 \mathrm{mg} / \mathrm{kg} \\
\text { u: } 0.448 \mathrm{mg} / \mathrm{kg} \\
\sigma_{\mathrm{p}}: 2.07 \mathrm{mg} / \mathrm{kg} \\
\text { robust } 0: 2.38 \mathrm{mg} / \mathrm{kg} \\
(11.7 \%)\end{array}$} & \multicolumn{2}{|c|}{$\begin{array}{c}\text { Material A } \\
\text { Zinc } \\
\text { CV: } 96.7 \mathrm{mg} / \mathrm{kg} \\
\text { u: } 1.23 \mathrm{mg} / \mathrm{kg} \\
\sigma_{\mathrm{p}}: 7.77 \mathrm{mg} / \mathrm{kg} \\
\text { robust } \sigma: 6.55 \mathrm{mg} / \mathrm{kg} \\
(6.77 \%)\end{array}$} & \multicolumn{2}{|c|}{$\begin{array}{c}\text { Material B } \\
\text { Copper } \\
\text { CV: } 133 \mathrm{mg} / \mathrm{kg} \\
\text { u: } 2.62 \mathrm{mg} / \mathrm{kg} \\
\text { Op: } 10.2 \mathrm{mg} / \mathrm{kg} \\
\text { robust } \sigma: 13.8 \mathrm{mg} / \mathrm{kg} \\
(10.3 \%)\end{array}$} & \multicolumn{2}{|c|}{ 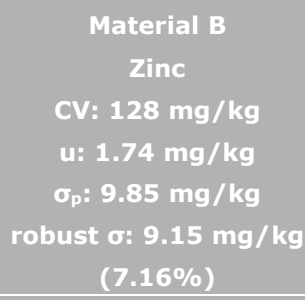 } \\
\hline & $\begin{array}{l}\text { Result } \\
\text { (mg/kg) }\end{array}$ & Za-score & $\begin{array}{l}\text { Result } \\
(\mathrm{mg} / \mathrm{kg})\end{array}$ & Za-score & $\begin{array}{c}\text { Result } \\
(\mathrm{mg} / \mathrm{kg})\end{array}$ & za-score & $\begin{array}{c}\text { Result } \\
(\mathrm{mg} / \mathrm{kg})\end{array}$ & Za-score \\
\hline PT8845 & 20.7 & 0.16 & 98.3 & 0.21 & 142 & 0.87 & 135 & 0.73 \\
\hline PT8847 & 22 & 0.79 & 88.7 & -1.02 & 135.6 & 0.24 & 106.8 & -2.13 \\
\hline PT8848 & 21.77 & 0.68 & 100.56 & 0.50 & 141.37 & 0.81 & 129.33 & 0.15 \\
\hline PT8849 & 20.1 & -0.13 & 97.4 & 0.10 & 136.3 & 0.31 & 134.1 & 0.64 \\
\hline PT8850 & 20.6 & 0.11 & 105.8 & 1.18 & 139.6 & 0.63 & 131.2 & 0.34 \\
\hline PT8851 & 17 & -1.63 & 98 & 0.17 & 115 & -1.78 & 121 & -0.69 \\
\hline PT8852 & 18.82 & -0.75 & 86.65 & -1.29 & 127.21 & -0.58 & 117.07 & -1.09 \\
\hline PT8853 & 18.4 & -0.95 & 89.6 & -0.91 & 125 & -0.80 & 129 & 0.12 \\
\hline PT8854 & 21.2 & 0.40 & 95.2 & -0.19 & 143 & 0.97 & 124 & -0.39 \\
\hline PT8855 & 19.37 & -0.48 & 90.67 & -0.77 & 118.82 & -1.40 & 115.76 & -1.22 \\
\hline PT8856 & 20 & -0.18 & 89 & -0.98 & 114 & -1.88 & 120 & -0.79 \\
\hline PT8857 & 86.376 & 31.88 & 12.822 & -10.79 & 98.397 & -3.41 & 93.035 & -3.53 \\
\hline PT8858 & 22.7 & 1.13 & 104 & 0.95 & 150 & 1.65 & 144 & 1.64 \\
\hline PT8859 & 16.8 & -1.72 & 96.9 & 0.03 & 111 & -2.17 & 115 & -1.30 \\
\hline PT8860 & 24.7 & 2.09 & 97.7 & 0.13 & 151 & 1.75 & 140 & 1.24 \\
\hline PT8861 & 22.161 & 0.86 & 91.037 & -0.72 & 148.637 & 1.52 & 127.344 & -0.05 \\
\hline PT8862 & 20.21 & -0.08 & 105.86 & 1.18 & 137.29 & 0.41 & 142.37 & 1.48 \\
\hline PT8863 & 25.45 & 2.45 & 97.09 & 0.06 & 145.36 & 1.20 & 128.22 & 0.04 \\
\hline PT8864 & 21 & 0.30 & 101 & 0.56 & 134 & 0.09 & 135 & 0.73 \\
\hline PT8865 & 20.8 & 0.21 & 99.4 & 0.35 & 146 & 1.26 & 137 & 0.93 \\
\hline PT8866 & 18.74 & -0.79 & 91.25 & -0.70 & 130.34 & -0.27 & 120.27 & -0.77 \\
\hline PT8867 & 24 & 1.75 & 124 & 3.52 & 158 & 2.44 & 161 & 3.37 \\
\hline PT8868 & 20.1 & -0.13 & 93 & -0.47 & 136 & 0.28 & 124 & -0.39 \\
\hline PT8869 & 19.97 & -0.19 & 101.67 & 0.65 & 114.78 & -1.80 & 127.83 & 0.00 \\
\hline PT8870 & 19.1 & -0.61 & 93 & -0.47 & 127 & -0.60 & 128 & 0.02 \\
\hline PT8871 & 21.9 & 0.74 & 96.51 & -0.02 & 140.06 & 0.68 & 117.6 & -1.04 \\
\hline PT8872 & 18 & -1.15 & 92 & -0.60 & 119 & -1.39 & 124 & -0.39 \\
\hline PT8873 & 20.1 & -0.13 & 99.1 & 0.31 & 145 & 1.16 & 134 & 0.63 \\
\hline PT8874 & 23 & 1.27 & 101 & 0.56 & 121 & -1.19 & 128 & 0.02 \\
\hline PT8875 & 24.1 & 1.80 & 118.6 & 2.82 & 176.3 & 4.23 & 161.5 & 3.42 \\
\hline PT8876 & 156 & 65.51 & 150 & 6.86 & & & & \\
\hline PT8878 & 20.6 & 0.11 & 92 & -0.60 & 140 & 0.67 & 129 & 0.12 \\
\hline PT8879 & 23.5 & 1.51 & 118 & 2.75 & 146 & 1.26 & 152 & 2.45 \\
\hline PT8880 & 21.3 & 0.45 & 96.59 & -0.01 & 142.8 & 0.95 & 129.7 & 0.19 \\
\hline PT8881 & 21 & 0.30 & 88 & -1.11 & 138 & 0.48 & 128 & 0.02 \\
\hline PT8882 & 17.2 & -1.53 & 99.6 & 0.38 & 124 & -0.89 & 123 & -0.49 \\
\hline PT8883 & 15.81 & -2.20 & 97.75 & 0.14 & 114.73 & -1.80 & 126.16 & -0.17 \\
\hline PT8885 & 17 & -1.63 & 96 & -0.08 & 118 & -1.48 & 127 & -0.08 \\
\hline PT8886 & 18.1 & -1.10 & 96.4 & -0.03 & 133 & -0.01 & 130 & 0.22 \\
\hline PT8887 & 19 & -0.66 & 93 & -0.47 & 131 & -0.21 & 129 & 0.12 \\
\hline PT8888 & 18.7 & -0.81 & 103 & 0.82 & 132 & -0.11 & 133 & 0.53 \\
\hline PT8889 & 19.4 & -0.47 & 96.1 & -0.07 & 135 & 0.18 & 129 & 0.12 \\
\hline PT8890 & 20 & -0.18 & 46.2 & -6.49 & 129 & -0.40 & 77.9 & -5.07 \\
\hline PT8891 & 17.9 & -1.19 & 94 & -0.34 & 124.5 & -0.85 & 119 & -0.89 \\
\hline
\end{tabular}

robust $\sigma=$ robust (relative) standard deviation based on participants' results 


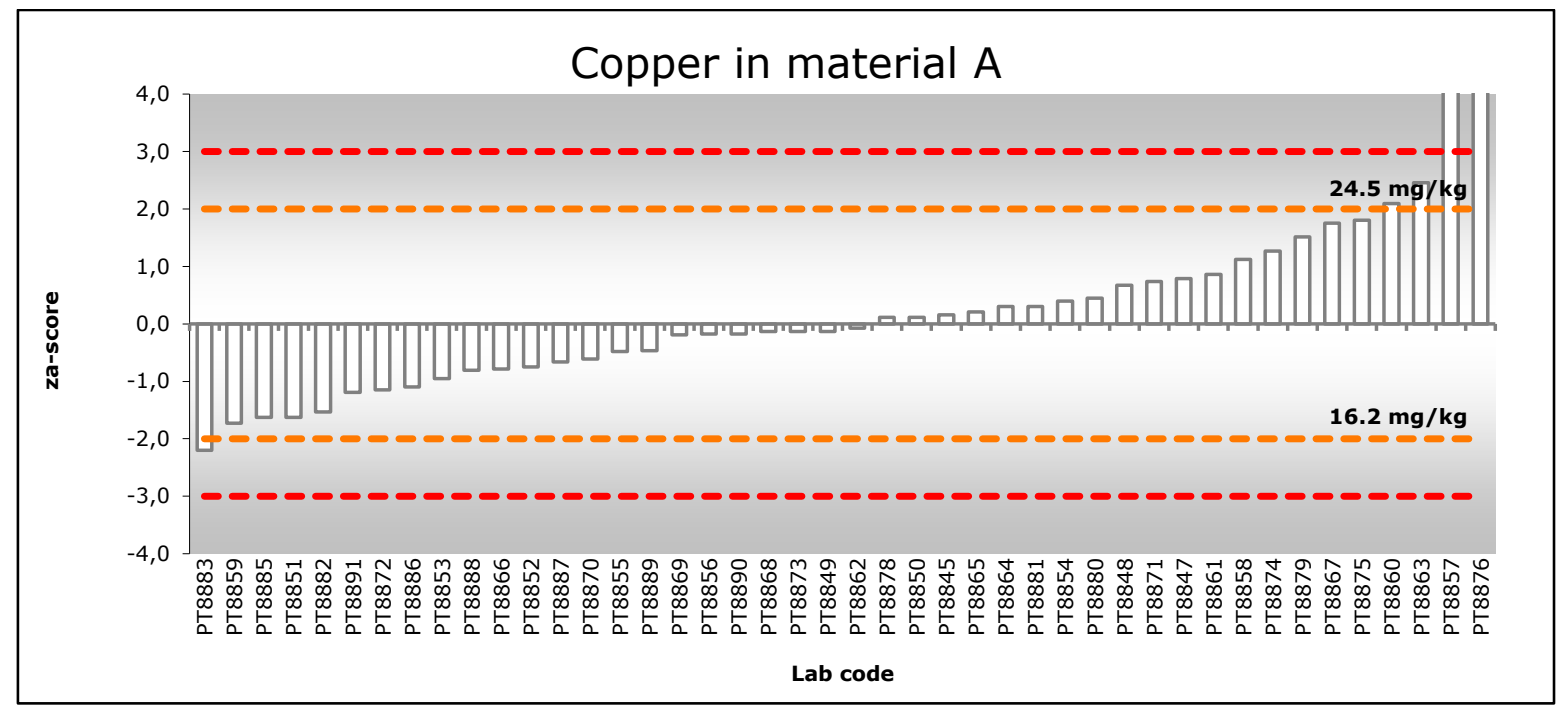

Figure a Graphical representation of the $z_{a}$-scores for copper in material $A$. The $X \pm 2 \sigma_{p}$ lines (dotted) are calculated according to equation I in $\$ 4.4$.

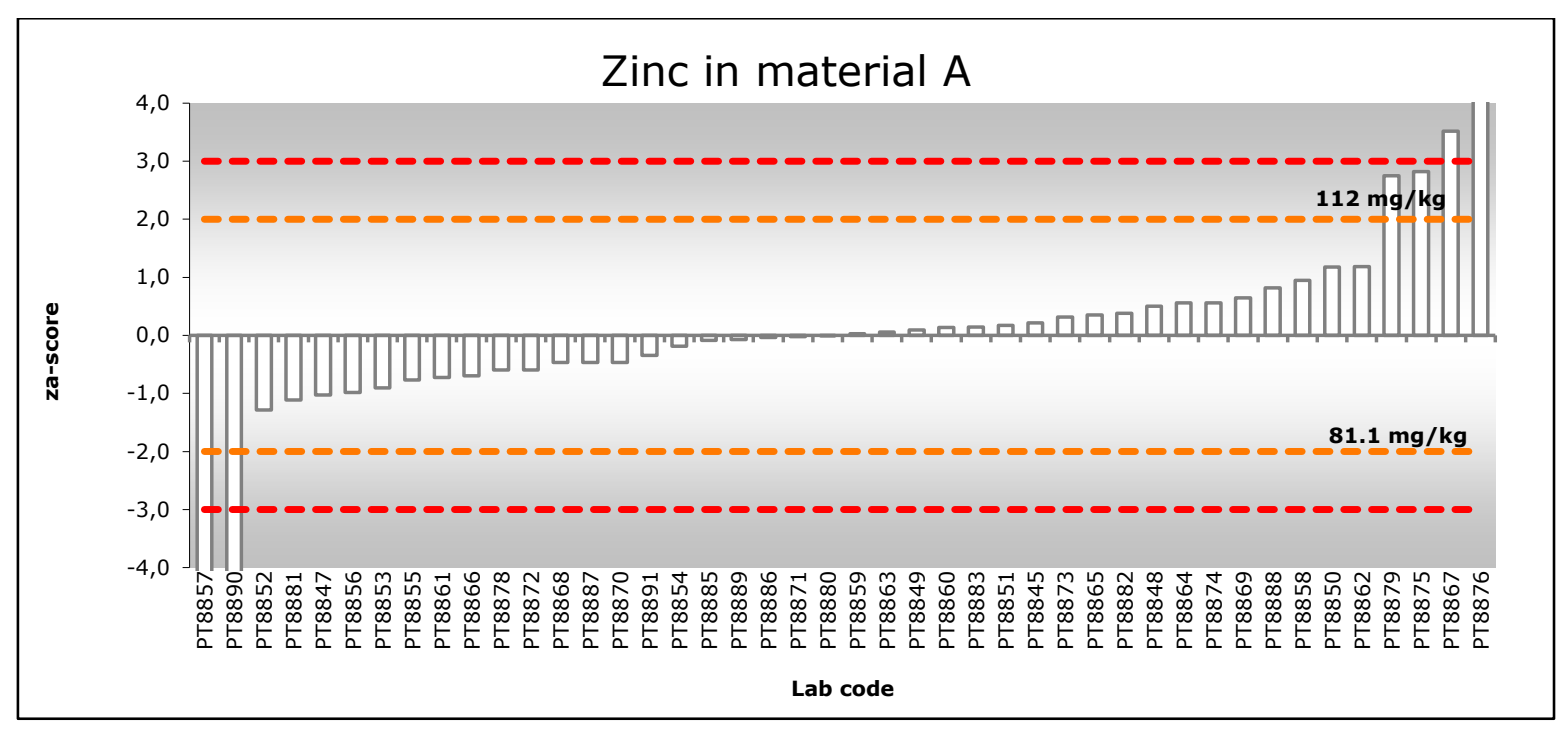

Figure $\boldsymbol{b} \quad$ Graphical representation of the $z_{a}$-scores for zinc in material $A$. The $X \pm 2 \sigma_{P}$ lines (dotted) are calculated according to equation I in $\$ 4.4$. 


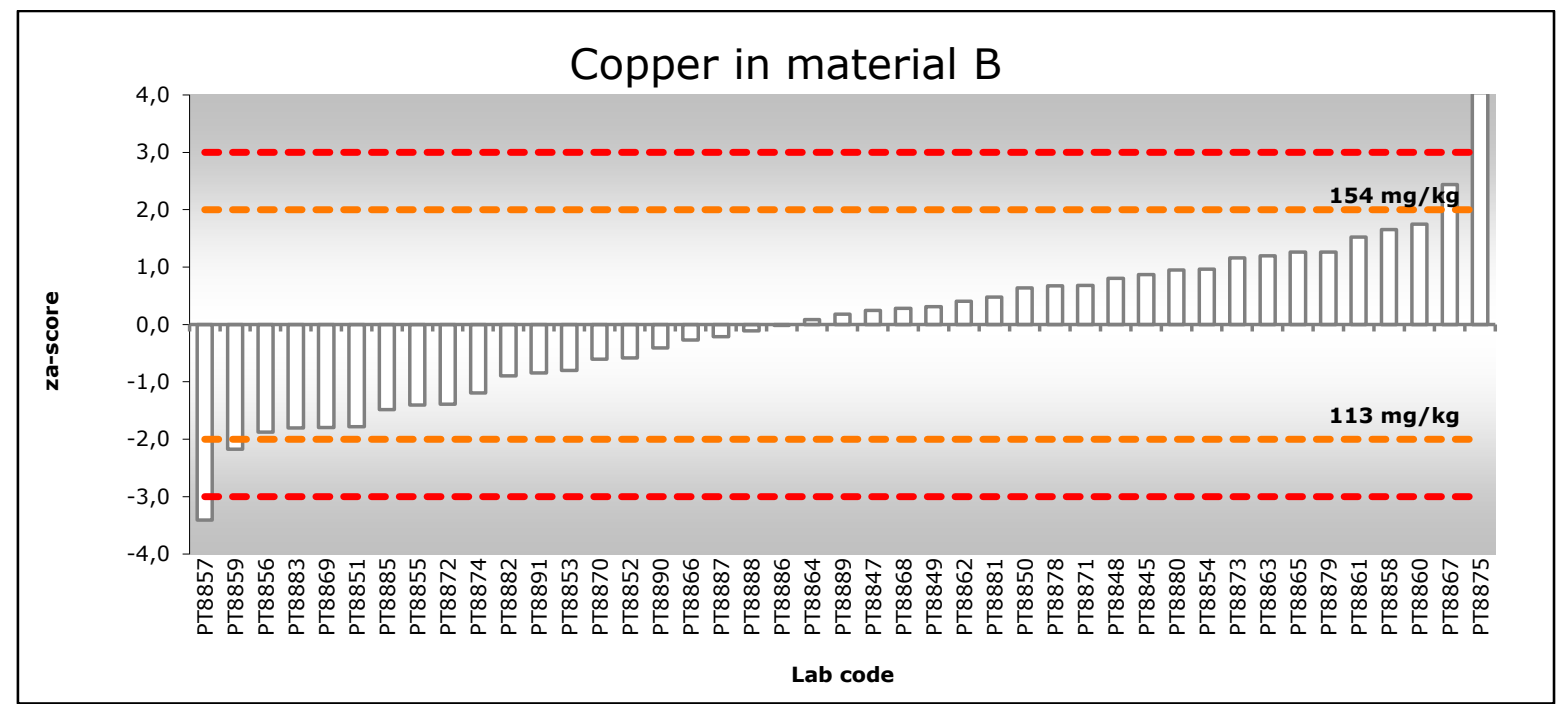

Figure $\boldsymbol{c} \quad$ Graphical representation of the $z_{a}$-scores for copper in material $B$. The $X \pm 2 \sigma_{p}$ lines (dotted) are calculated according to equation I in \$4.4.

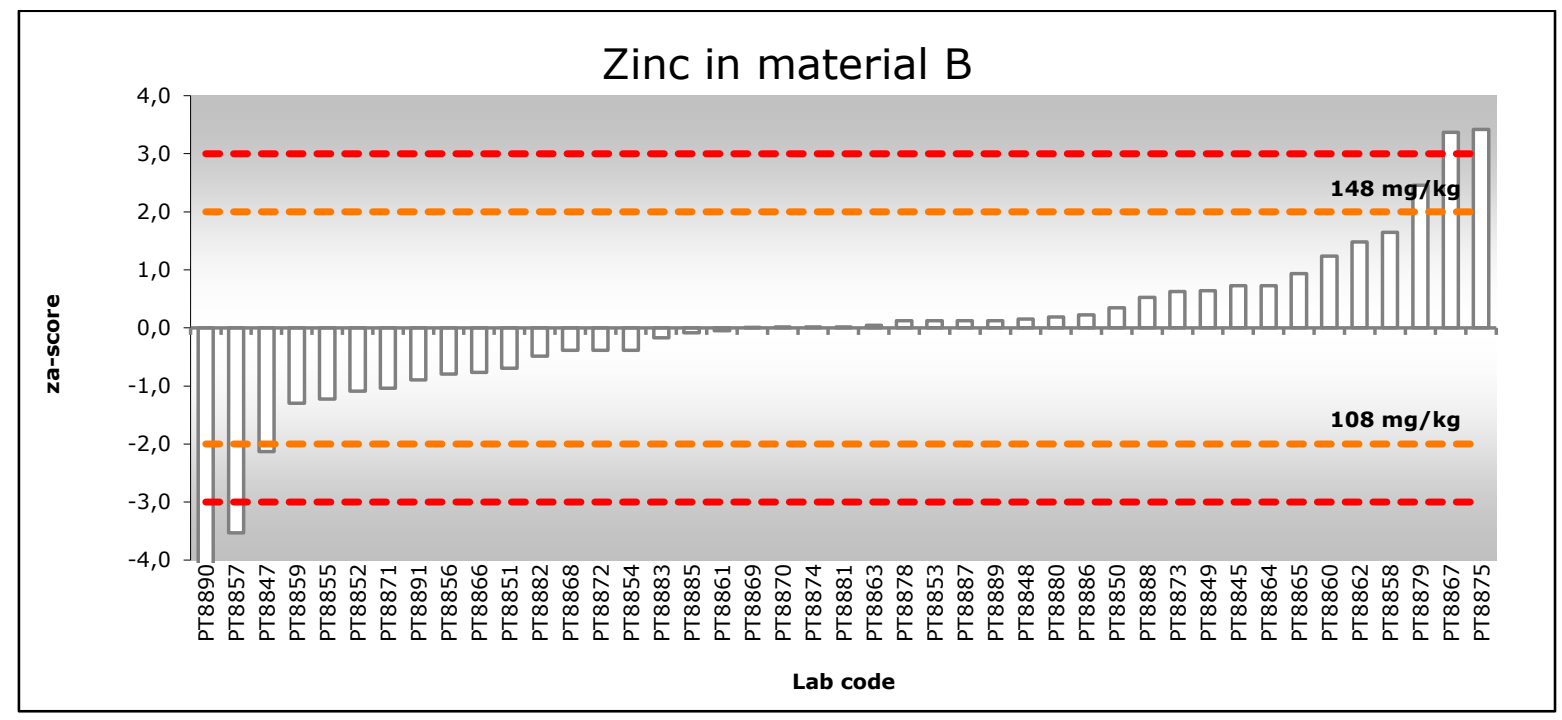

Figure d Graphical representation of the $z_{a}$-scores for zinc in material $B$. The $X \pm 2 \sigma_{P}$ lines (dotted) are calculated according to equation I in $\$ 4.4$. 


\section{Annex 7 Overview performance per laboratory}

\begin{tabular}{|c|c|}
\hline Laboratory code & Satisfactory performance \\
\hline PT8845 & 4 out of 4 , optimal performance \\
\hline PT8847 & 3 out of 4 \\
\hline PT8848 & 4 out of 4 , optimal performance \\
\hline PT8849 & 4 out of 4 , optimal performance \\
\hline PT8850 & 4 out of 4 , optimal performance \\
\hline PT8851 & 4 out of 4 , optimal performance \\
\hline PT8852 & 4 out of 4 , optimal performance \\
\hline PT8853 & 4 out of 4 , optimal performance \\
\hline PT8854 & 4 out of 4 , optimal performance \\
\hline PT8855 & 4 out of 4 , optimal performance \\
\hline PT8856 & 4 out of 4 , optimal performance \\
\hline PT8857 & 0 out of 4 \\
\hline PT8858 & 4 out of 4 , optimal performance \\
\hline PT8859 & 3 out of 4 \\
\hline PT8860 & 3 out of 4 \\
\hline PT8861 & 4 out of 4 , optimal performance \\
\hline PT8862 & 4 out of 4 , optimal performance \\
\hline PT8863 & 3 out of 4 \\
\hline PT8864 & 4 out of 4 , optimal performance \\
\hline PT8865 & 4 out of 4 , optimal performance \\
\hline PT8866 & 4 out of 4 , optimal performance \\
\hline PT8867 & 1 out of 4 \\
\hline PT8868 & 4 out of 4 , optimal performance \\
\hline PT8869 & 4 out of 4 , optimal performance \\
\hline PT8870 & 4 out of 4 , optimal performance \\
\hline PT8871 & 4 out of 4 , optimal performance \\
\hline PT8872 & 4 out of 4 , optimal performance \\
\hline PT8873 & 4 out of 4 , optimal performance \\
\hline PT8874 & 4 out of 4 , optimal performance \\
\hline PT8875 & 1 out of 4 \\
\hline PT8876 & 0 out of $2^{*}$ \\
\hline PT8878 & 4 out of 4 , optimal performance \\
\hline PT8879 & 2 out of 4 \\
\hline PT8880 & 4 out of 4 , optimal performance \\
\hline PT8881 & 4 out of 4 , optimal performance \\
\hline PT8882 & 4 out of 4 , optimal performance \\
\hline PT8883 & 3 out of 4 \\
\hline PT8885 & 4 out of 4 , optimal performance \\
\hline PT8886 & 4 out of 4 , optimal performance \\
\hline PT8887 & 4 out of 4 , optimal performance \\
\hline PT8888 & 4 out of 4 , optimal performance \\
\hline PT8889 & 4 out of 4 , optimal performance \\
\hline PT8890 & 2 out of 4 \\
\hline PT8891 & 4 out of 4 , optimal performance \\
\hline
\end{tabular}

*Participant PT8876 analyse only one sample 
Wageningen Food Safety Research

P.O. Box 230

6700 AE Wageningen

The Netherlands

T +31 (0)317480256

www.wur.eu/food-safety-research

WFSR report 2021.015
The mission of Wageningen University \& Research is "To explore the potential of nature to improve the quality of life". Under the banner Wageningen University \& Research, Wageningen University and the specialised research institutes of the Wageningen Research Foundation have joined forces in contributing to finding solutions to important questions in the domain of healthy food and living environment. With its roughly 30 branches, 6,800 employees (6,000 fte) and 12,900 students, Wageningen University \& Research is one of the leading organisations in its domain. The unique Wageningen approach lies in its integrated approach to issues and the collaboration between different disciplines. 



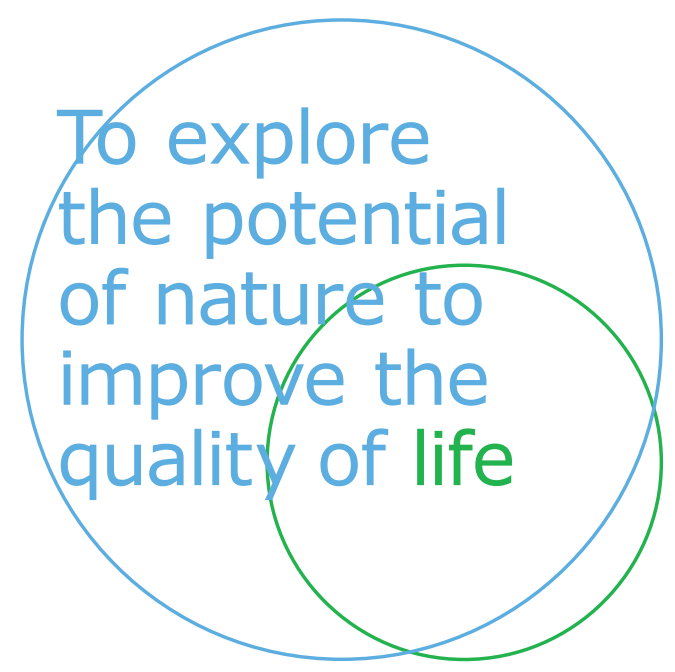

Wageningen Food Safety Research P.O. Box 230

6700 AE Wageningen

The Netherlands

T +31 (0)317480256

www.wur.eu/food-safety-research

WFSR report 2021.015
The mission of Wageningen University \& Research is "To explore the potential of nature to improve the quality of life". Under the banner Wageningen University \& Research, Wageningen University and the specialised research institutes of the Wageningen Research Foundation have joined forces in contributing to finding solutions to important questions in the domain of healthy food and living environment. With its roughly 30 branches, 6,800 employees $(6,000 \mathrm{fte})$ and 12,900 students, Wageningen University \& Research is one of the leading organisations in its domain. The unique Wageningen approach lies in its integrated approach to issues and the collaboration between different disciplines. 